\title{
Proceeding
}

Supplementary Issue: Spring Conferences of Sports Science. Costa Blanca Sports Science Events, 14-15 June 2019. Alicante, Spain.

\section{Basketball and ankle injuries}

\author{
GIOVANNI FALCONE ${ }^{1} \unlhd$, RAFFAELE SCURATI², FRANCESCA D'ELIA ${ }^{1}$, TIZIANA D'ISANTO1 \\ ${ }^{1}$ University of Salerno, Italy \\ 2University of Milan, Italy
}

\begin{abstract}
The aim is to demonstrate how an ankle injury appears to be a serious problem and that, as such, it must be adequately addressed to prevent it from recurring in the future because, as evidenced by recent studies, the risk of a relapse it is greater if there are precedents not completely rehabilitated. This study also wants: 1) to list all the factors that predispose the onset of an ankle injury; 2) describe the different types of ankle injuries; 3 ) set out guidelines on prevention and post-injury recovery. Finally, we will see how accidents in basketball are almost identical for both professional athletes and occasional practitioners of this discipline. Injuries cannot be completely prevented because given the variability of factors it's really great and it's almost impossible to make an accurate prediction on a specific joint. Performing specific exercises, however, is a great way to minimize the chance of an injury and consequently increase the physical and mental health of the athlete. Keywords: Basketball; Training; Prevention; Port cares.
\end{abstract}

\section{Cite this article as:}

Falcone, G., Scurati, R., D'Elia, F., \& D'Isanto, T. (2019). Basketball and ankle injuries. Journal of Human Sport and Exercise, 14(4proc), S1142-S1148. doi:https://doi.org/10.14198/ihse.2019.14.Proc4.79

Corresponding author. University of Salerno, Italy.

E-mail: giov.falcone@hotmail.com

Supplementary Issue: Spring Conferences of Sports Science. Costa Blanca Sports Science Events, 14-15 June 2019. Alicante, Spain.

JOURNAL OF HUMAN SPORT \& EXERCISE ISSN 1988-5202

(c) Faculty of Education. University of Alicante

doi:10.14198/jhse.2019.14.Proc4.79

S1142 | 2019| Proc4 | VOLUME 14

C 2019 University of Alicante 


\section{INTRODUCTION}

When we talk about injuries in basketball, we must always concentrate on analysing the movements that athletes perform (Raiola, 2017, Raiola, 2013). In fact, depending on the various positions in the field (Altavilla, Raiola, 2019, 2015, 2014) the athlete is subjected to different forces and consequently to different stresses affecting the joints. An injury is a serious problem for the athlete's state of health and should be addressed as such.

\section{Analysis of fundamental movements}

All the movements and movements that a basketball player makes, originate from the Fundamental Position or Power Position, which is realized with bent legs and with a knee flexion angle of $120^{\circ}$. Starting from this position, the athlete will be able to perform all fundamental offensive technical movements, i.e. dribbling, passing and shooting, and defensive technical movements.

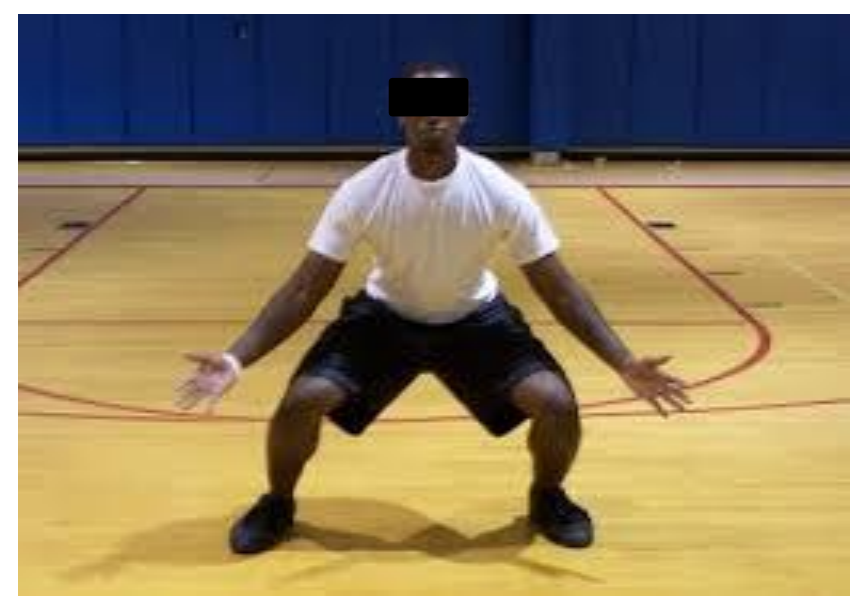

Figure 1. Power position.

The fundamental position is difficult to find and above all it is very tiring to maintain during a game, it is also useful to specify that not all players can reach the same fundamental position, as each player has different characteristics from the others and the correct achievement of the fundamental position depends on various factors (McKay et al.2001):

- $\quad$ Good mobility of the ankle joint;

- $\quad$ Good lengthening of the posterior kinetic chain;

- Mobility of hip bone;

- $\quad$ Proper activation of the stabilizer muscles of the CORE;

- $\quad$ Good mobility of the bachelor-humeral joint;

- $\quad$ Coordination of lower limb movements with the upper ones.

The technical movements that originate from the Power Position are: 1) Defensive slips; 2) Change of direction.

1) Defensive slips: Defensive slips are lateral displacements that allow to keep the body position constant with respect to the attacker. 


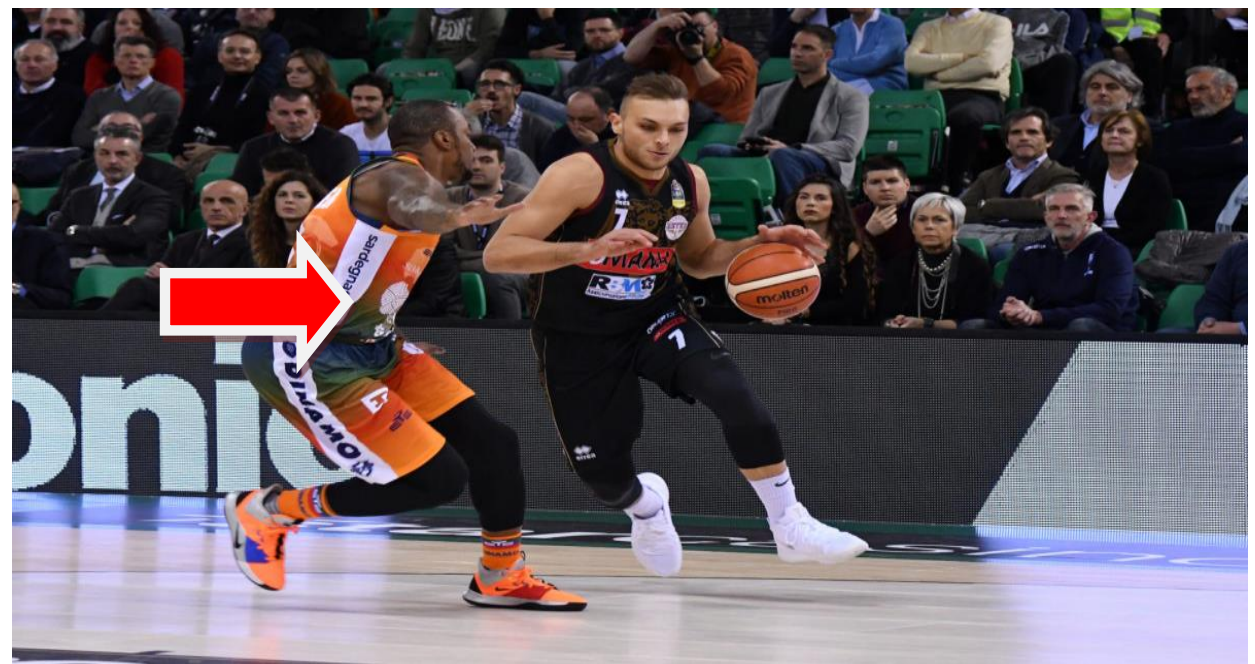

Figure 2. Defensive slips.

2) Change of direction: the change of direction is used to beat an opponent or unmark. The change of direction is realized when the player places the opposite foot to the direction he intends to take, slows down the race and at the same times pushes the weight of the body towards the new direction.

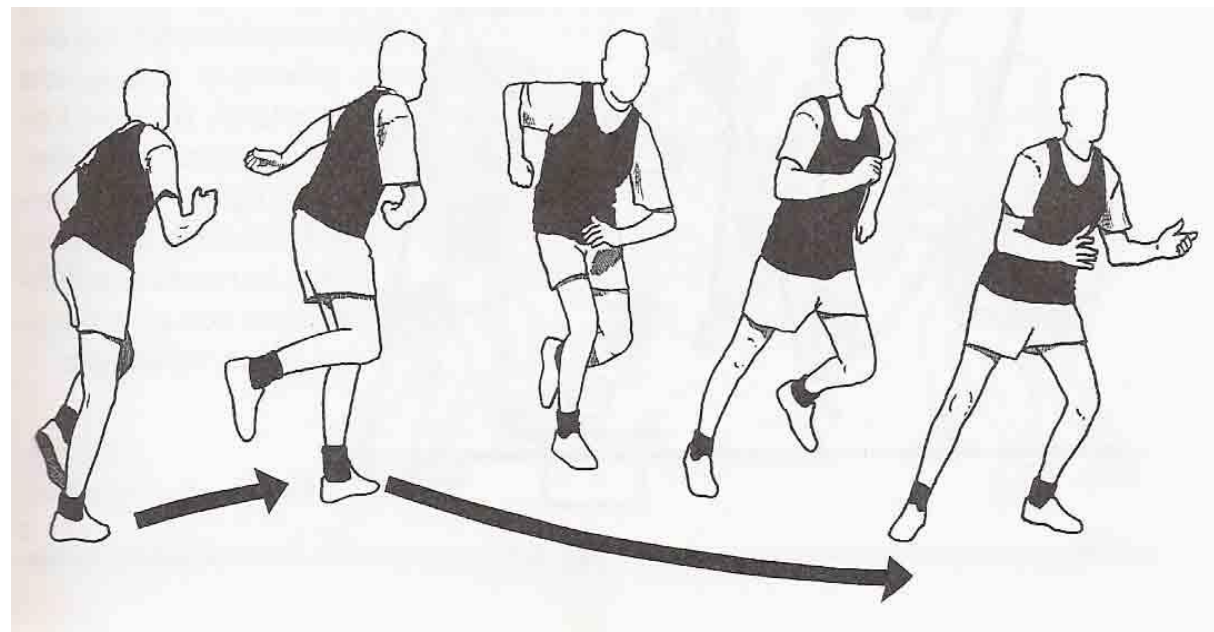

Figure 3. Change of direction.

\section{ANKLE INJURIES}

The ankle joint is the joint most exposed to injuries, in fact, ankle sprain is the most frequent trauma in basketball practice. $70 \%$ of the players suffered at least one injury to ankle sprain in their career. of these:

- $85 \%$ occurs with inversion mechanism;

- $5 \%$ eversion mechanism

In the event that the distortion turns out to be recurrent and chronic, we could arrive at the pathological condition known as "CAl" or Chronic-Ankle-Instability. In addition to the stress factor, there are a number of 
factors that increase the probability of injury to the ankle joint. These factors can be of various types, including:

- Structural factors;

- Strength deficit

- Reduced proprioceptive control.

Injuries typical of basketball can generally be traced to two types of factors:

- Intrinsic factors;

- Extrinsic factors.

As for the intrinsic factors, in most cases, they derive above all from the management of the ball and an increased aggressiveness and intensity of the physical contacts during the various phases of the game. Neusel E., Loffelholz M., Breuer A., in 1996, conducted a research on the basketball players of the German National Basketball team, highlighting that the injurious mechanisms mostly concern limbs less than $67.5 \%$ (Neusel et al, 1996). In particular McKay and Goldie, agree in affirming that the most frequent lesion in basketball is the tibio-tarsal joint.

Extrinsic factors, on the other hand, are considered the most easily correctable factors, since most of these include:

- Footwear;

- The temperature inside the training court;

- The field;

- Bandages.

\section{ACCIDENT PREVENTION AND RECOVERY}

When it comes to prevention, in general, reference is made to a series of jobs that aim to reduce the risk of injury. It is important to know that an injury cannot be completely prevented (Alberti et al, 2014), due to the enormous variety of factors that cause it. What can be done, on the other hand, is to reduce the incidence, or the number of injuries by structuring a preventive training program that will aim to minimize the risk of injury and / or relapse. The preventive work program (Invernizzi et al., 2019) must always be inserted within each individual training session, as individual isolated sessions are not enough. Clearly the preventive program must:

- Activate the CORE;

- Improve proprioception;

In the specific case of the ankle, a traumatic event such as distortion, induces a functional and biomechanical imbalance. At the same time, a badly recovered distortion leads to deficiency of back flexion, reducing the mobility of the joint itself and the possibility of assuming correct positions during play. A preventive program for the prevention of ankle injuries must follow this progression:

1) Improve mobility;

2) Reinforcement of kinetic chains;

3) Improve stability with proprioception exercises. 


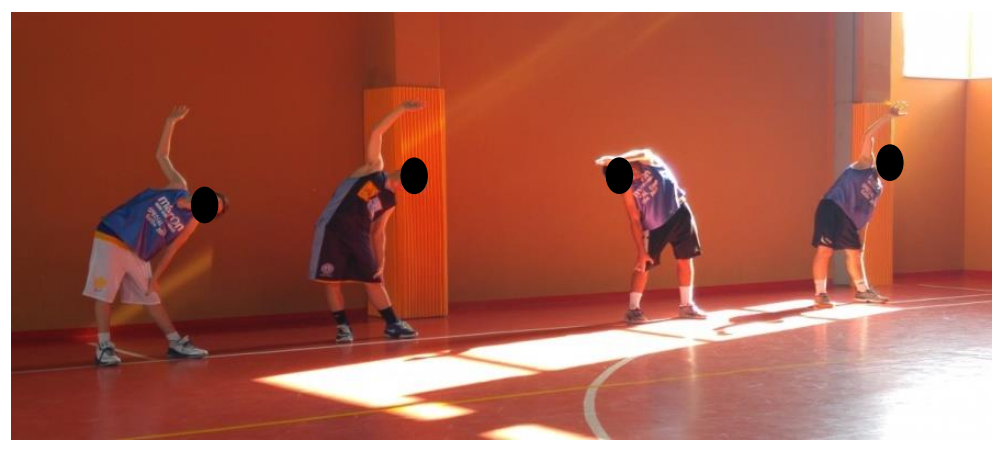

Figure 4. Kinetic chains reinforcement.

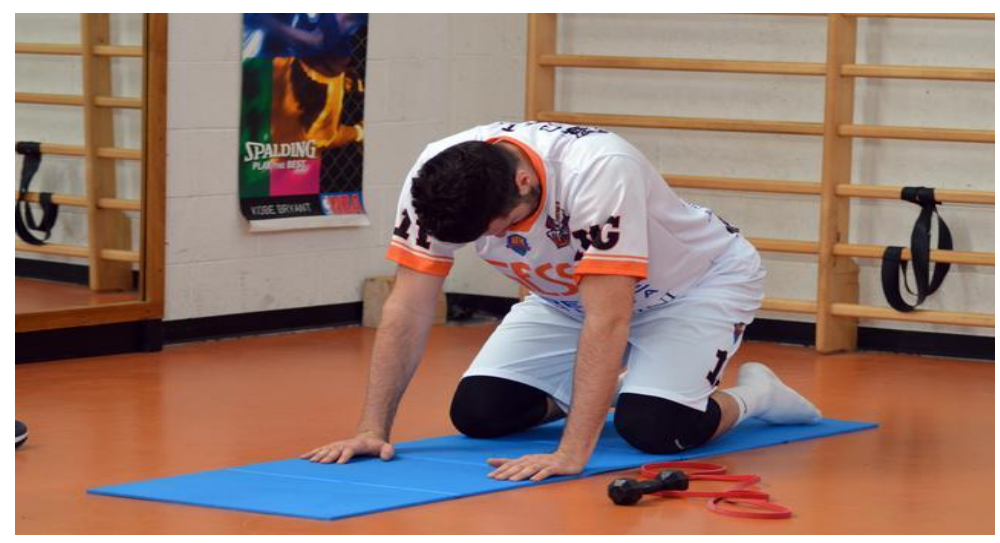

Figure 5. Mobility exercises.

From the premises given above, it is clear that the return to competitive practice is absolutely a process that must be planned down to the smallest detail, taking care not to leave anything out as it could be to the detriment of the athlete. Before returning to the field it is necessary to recover elasticity, muscle tone and proprioception.

The recovery of elasticity passes through the enhancement of the degree of elongation of the muscle groups that are inserted on the joint concerned, so it is particularly important to stretch, be it dynamic or static.

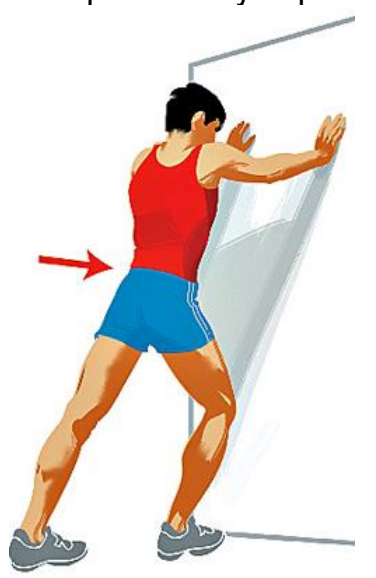

Figure 6. Static stretching. 
The recovery of muscle tone is one of the key points for the reintegration of the athlete. Since the ankle is a mainly ligamentous joint, the muscle tone indirectly acts to make it more stable.
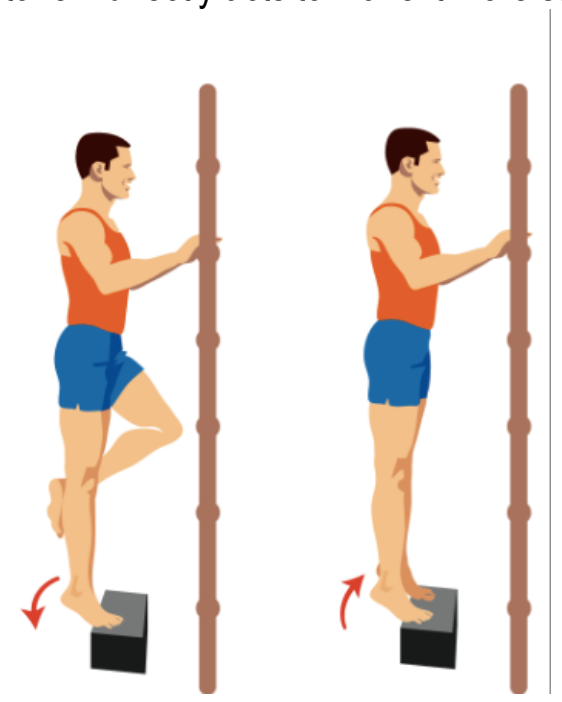

Figure 7. Recovery muscle tone.

The recovery of proprioception reduces the likelihood of relapsing, and exponentially increases the athletic ability of the basket. With an aid placed below the plantar arch, it is possible to perform dynamic monopodalic loading exercises, alternating the two lower limbs.

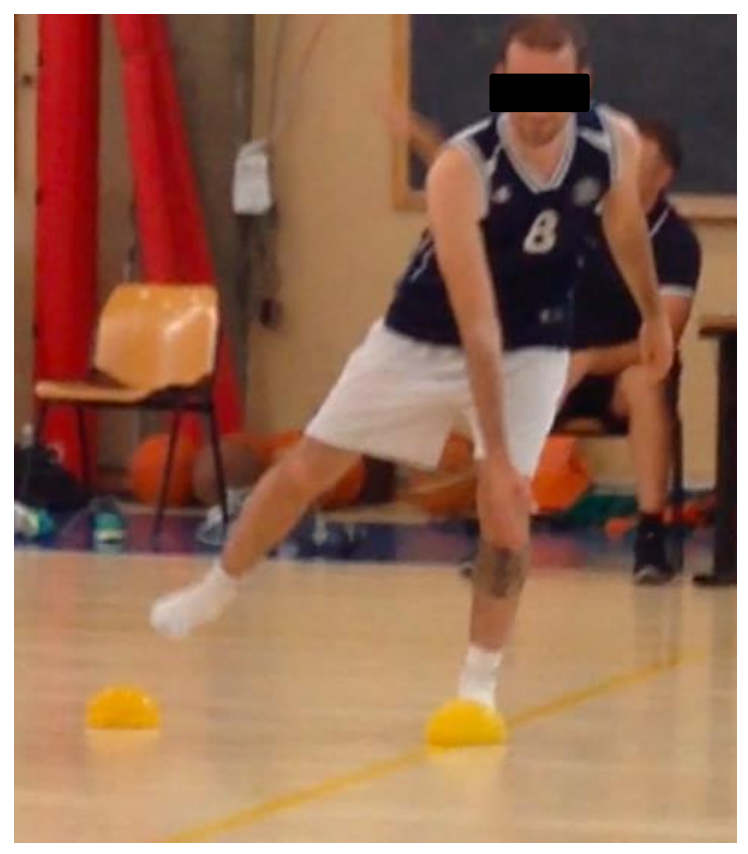

Figure 8. Proprioception exercise. 


\section{CONCLUSIONS}

As already widely said, preventing an injury completely is not possible, also taking into consideration that prevention is a general and non-specific concept. What you can do instead is prepare the body of the athlete for the stresses and stresses of playing basketball with targeted exercises, following the logic of "movements on the field" which is different between sport and sport. Through preabilization we prepare the body of our athlete for optimal functioning for basketball. A pre-qualification program must have as its objective:

1) Activation of the neuro-muscular system;

2) Being multi-articular;

3) Improve stability;

4) Recall the game movement.

"With preabilization, we try to build strength and stability around the most vulnerable areas, while improving mobility, balance and joint function. Since pre-activation addresses the muscular imbalances that lead to injuries, it helps prevent many injuries."(Verstegen, Williams, 2006).

\section{REFERENCES}

Altavilla, G., Raiola, G. (2019) A brief review on physiological commitment in basketball: An interpretative key, Journal of Human Sport and Exercise, 14, pp. S59-S65. https://doi.org/10.14198//hse.2019.14.proc1.07

Altavilla, G., Raiola, G. (2015) Sports game tactic in basketball, Sport Science, 8 (1), pp. 43-46.

Altavilla, G., Raiola, G. (2014) Global vision to understand the game situations in modern basketball, Journal of Physical Education and Sport, 14 (4), pp. 493-496.

Raiola, G. (2017) Motor learning and teaching method, Journal of Physical Education and Sport, 17, art. no. 236, pp. 2239-2243.

Raiola, G. (2013) Body knowledge and motor skills, Knowledge Cultures, 1 (6), pp. 64-72.

\section{(c) $\underset{\mathrm{EY} \text { (i) }}{\mathrm{Y} \text { ND }}$}

This work is licensed under a Attribution-NonCommercial-NoDerivatives 4.0 International (CC BY-NC-ND 4.0). 